\title{
A eficácia da gestão fiscal em escala subnacional no Brasil
}

\author{
Maria Rosicleide Nascimento Araújo \\ Mônica Aparecida Rocha Silva \\ Waldecy Rodrigues
}

\begin{abstract}
Resumo
Considerando o arcabouço teórico de governança pública para resultados, o objetivo deste artigo é demonstrar em que medida os agentes fazendários percebem a eficácia da metodologia de avaliação Maturidade e Desempenho da Gestão Fiscal (MD-GEFIS) enquanto instrumento de governança da gestão fiscal subnacional brasileira. Aplicou-se questionários para verificar o entendimento dos agentes fazendários quanto às caraterísticas de governança pública e de ferramenta de gestão. Com base na análise de conteúdo das respostas obtidas, concluiu-se que a maioria considera a metodologia eficaz, na medida em que seus resultados podem contribuir para a melhoria da transparência da gestão fiscal, o aumento da arrecadação e o melhor uso dos recursos públicos. Contudo, para que seus resultados sejam críveis, fidedignos e aceitáveis, fazem-se necessárias: a correta coleta dos indicadores, a consideração das especificidades das unidades avaliadas e que sua aplicação não seja caracterizada como autoavaliação, cabendo que esta seja conduzida por especialistas externos às unidades.
\end{abstract}

Palavras-chave | Brasil; eficácia; governança pública para resultados; MD-GEFIS.

Classificação JEL | E62 H30 H83

\section{Fiscal management effectiveness on a sub-national scale in Brazil}

\begin{abstract}
Considering the theoretical framework of public governance for results, the aim of this article is to demonstrate the extent to which farm agents perceive the effectiveness of the Fiscal Management Maturity and Performance Assessment Methodology (MD-GEFIS) as a governance instrument for Brazilian subnational fiscal management. Questionnaires were applied to verify the understanding of the treasury agents regarding the characteristics of public governance and management tool. Based on the content analysis of the responses obtained, it was concluded that the majority considers the methodology effective, as its results can contribute to improving the transparency of fiscal management, increasing tax revenue and making better use of public resources. However, for their results to be credible, reliable and acceptable, it is necessary: the correct collection of indicators, the consideration of the
\end{abstract}


specificities of the evaluated units and that their application is not characterized as selfassessment, which should be conducted by experts external to the units.

Keywords | Brazil; effectiveness; public governance for results; MD-GEFIS.

JEL Classification | E62 H30 H83

\section{La eficacia de la gestión fiscal a escala subnacional en Brasil}

\section{Resumen}

Considerando el marco teórico de gobernanza pública para resultados, el objetivo de este artículo es demostrar en qué medida los agentes hacendados perciben la eficacia de la metodología de evaluación de la Madurez y el Rendimiento de la Gestión Fiscal (MD-GEFIS) como instrumento de gobernanza de la gestión fiscal subnacional brasileña. Se aplicaron cuestionarios para verificar el entendimiento de los hacendados en cuanto a las características de gobierno público y de herramienta de gestión. Con base en el análisis de contenido de las respuestas obtenidas, se concluye que la mayoría considera la metodología eficaz, en la medida en que sus resultados pueden contribuir a la mejora de la transparencia de la gestión fiscal, el aumento de la recaudación y el mejor uso de los recursos públicos. Sin embargo, para que sus resultados sean creíbles, fidedignos y aceptables, se hace necesaria la correcta recolección de los indicadores, la consideración de las especificidades de las unidades evaluadas, y que su aplicación no sea caracterizada como de autoevaluación, siendo necesario que sea conducida por expertos externos a las unidades.

Palabras clave | Brasil; eficacia; gobernanza pública para resultados; MD-GEFIS.

Clasificación JEL | E62 H30 H83

\section{Introdução}

Com as constantes crises social, política e econômica, que se refletem no âmbito fiscal, e a exigência da sociedade por serviços públicos mais eficientes com melhor desempenho e resultados, ampliaram-se as discussões sobre a institucionalização de boas práticas na gestão pública. Grosso modo, objetivam a otimização da utilização dos recursos públicos por parte do Estado, com maior eficiência, eficácia e efetividade - princípios da governança pública.

A despeito da diversidade de conceitos de governança pública, adotou-se aqui o do Tribunal de Contas da União (TCU) (BRASIL, 2014), que a define como sendo aquela que contém os instrumentos de liderança, os estratégicos e os de comando, utilizados na avaliação, direção e monitoramento das ações governamentais com fins de conduzir as políticas públicas e os serviços que interessam à sociedade. 
Desde a década de 1990, o Brasil vem adotando princípios de gestão pública voltada para resultados e para a qualidade e eficiência dos serviços públicos. Mais precisamente desde o ano de 1995, com a difusão dos princípios do New Public Management (NPM).

No âmbito da gestão fiscal subnacional brasileira, desde 1996 nota-se avanços significativos na definição de políticas e prioridades, consequência de programas de modernização fazendária. Um primeiro ciclo ocorreu entre 1996 e 2006, com o Programa Nacional de Apoio à Modernização Fiscal (PNAFE) financiado pelo Banco Interamericano de Desenvolvimento (BID) e o Programa de Modernização da Administração Fiscal (PMAT) com recursos do Banco Nacional de Desenvolvimento Econômico Sustentável (BNDES). O segundo, ainda em andamento, iniciou em 2009 com o Programa de Apoio à Gestão e Integração dos Fiscos no Brasil (Profisco), financiado pelo BID, cujo montante ultrapassou os US\$ 600 milhões. Um terceiro ciclo, também custeado pelo BID, já está em andamento, e o montante de recursos liberados pelo banco deve ultrapassar os US\$900 milhões (COGEF, 2016).

Com o desenvolvimento dos primeiros ciclos, o BID, apoiado pela Secretaria Executiva do Ministério da Fazenda (SE/MF) e pelo Conselho Nacional de Política Fazendária (Confaz), elaborou relatórios de avaliação nos anos 2009, 2013 e 2014. Os resultados apontaram a existência de uma dificuldade comum relacionada ao processo de monitoramento e avaliação da gestão fiscal, em específico aos resultados dos programas de modernização, isto é, uma deficiência na metodologia e no conjunto de indicadores da gestão fiscal (COGEF, 2016).

Objetivando resolver essa questão, o BID, em conjunto com representantes da SE/MF e diversos grupos do Confaz, realizaram entre os anos de 2015 e 2016 a construção de um método de avaliação da gestão fiscal dos estados e Distrito Federal. Essa metodologia, denominada de Maturidade e Desempenho da Gestão Fiscal (MD-GEFIS), tem como objetivo principal contribuir para a melhoria dos resultados da gestão fiscal, em específico os relativos ao aumento da transparência, da arrecadação, e, ainda, da eficiência do gasto público (COGEF, 2016).

A MD-GEFIS avalia o nível de amadurecimento dos processos da gestão fiscal, sobre isto, Figueiredo e Figueiredo (1986) entendem que a avaliação de processos objetiva aferir a eficácia, considerada como a relação entre os objetivos e instrumentos explícitos de um determinado programa e seus resultados efetivos, ou seja, as metas propostas realmente alcançadas.

Diante deste contexto, o presente trabalho pretende tratar da eficácia desse modelo de avaliação, considerando o arcabouço teórico da governança pública para resultados. Assim, o questionamento do presente estudo é: na opinião da gestão fazendária estadual beneficiada com o Profisco e que já aplicou a MD-GEFIS, esse modelo cumpriu com os objetivos pretendidos na sua formulação, em especial, ele tem sido um instrumento relevante para a governança da gestão fazendária? 
Como objetivo geral, pretende-se demonstrar em que medida os agentes fazendários percebem a eficácia da MD-GEFIS como instrumento de governança da gestão fiscal subnacional brasileira. Neste sentido, tem-se as seguintes metas especificas: i) levantar por meio da aplicação de questionário, as informações do entendimento dos agentes fazendários sobre a eficácia dessa metodologia; ii) identificar a partir dos resultados do questionário aplicado, a opinião dos agentes fazendários quanto às caraterísticas de governança pública da avaliação; e iii) analisar teoricamente com base em eficácia e governança pública, os resultados percebidos junto aos gestores fiscais subnacionais referentes à MD-GEFIS como ferramenta de gestão.

Este artigo está estruturado em cinco seções, incluindo esta introdução. Na segunda seção tem-se a discussão teórica conceitual sobre governança e gestão pública para resultados. A seção seguinte aborda os procedimentos metodológicos aplicados no trabalho. Os resultados são discutidos na quarta seção, sendo que as considerações finais estão na quinta última seção.

\section{Teorias e conceitos de governança e gestão pública para resultados}

No atual cenário de crise política, social e econômica, que também se reflete na esfera fiscal, a sociedade brasileira tem exigido serviços pautados pelo uso racional dos recursos públicos, pelo comprometimento com o excelente desempenho e com os seus resultados.

Isto tem ampliado as discussões sobre a necessidade da instituição de boas práticas gerenciais na gestão pública. Essas medidas, em geral, têm o propósito de otimizar a aplicação dos recursos públicos fazendo com que a gestão do Estado seja mais eficiente, o que nos leva à questão da governança pública.

Diversas entidades nacionais e internacionais têm buscado definir governança pública, contudo, não existe um termo unânime, isto porque, de acordo com Oliveira e Pisa (2015), este conceito tem evoluído ao longo do tempo, adaptandose às diversas sociedades e culturas em que foi adotado.

Para Martins e Marini (2010), governança pública é um constructo complexo e um termo do momento, sendo considerado um novo paradigma, baseado em novas teorias, como a de redes e a do institucionalismo sociológico. Já para Matias-Pereira (2010), governança pública pode ser entendida como um sistema determinante para o equilíbrio de poder entre os stakeholders (cidadãos, governantes, alta administração, gestores e colaboradores), e objetiva a prevalência do bem comum sobre os interesses de pessoas ou grupos.

Neste trabalho, utilizou-se o conceito de governança no setor público adotado pela TCU (BRASIL, 2014), qual seja: aquela que compreende essencialmente os 
mecanismos de liderança, estratégia e controle, postos em prática para avaliar, direcionar e monitorar a atuação da gestão com vistas à condução de políticas públicas e à prestação de serviços de interesse da sociedade.

Neste sentido, os 3Es da governança pública aqui conceituados e adotados são: eficácia - a relação entre as metas, objetivos e instrumentos propostos em um determinado programa e seus resultados alcançados; eficiência - a relação entre o esforço empregado e os resultados obtidos; e efetividade - relativo ao sucesso ou fracasso em termos de uma efetiva mudança nas condições sociais prévias das populações atingidas (FIGUEIREDO; FIGUEIREDO, 1986; ARRETCHE, 1998).

No Brasil, desde a década de 1990, princípios de gestão pública voltada para resultados ${ }^{1}$, qualidade e eficiência dos serviços públicos vêm sendo adotados. Inicialmente, em 1995, com a difusão dos princípios do New Public Management $(\mathrm{NPM})^{2}$, e, posteriormente, com a implementação de outras iniciativas legais, como por exemplo a Emenda Constitucional n ${ }^{\circ} 19 / 1998^{3}$, a Lei de Responsabilidade Fiscal (LRF) N. 101/20004. Além disso, instrumentos de gestão pública, considerados inovadores, foram introduzidos como os contratos de gestão, os planos plurianuais, os programas de qualidade, e a otimização de processos promovida pela intensiva utilização da tecnologia da informação (COGEF, 2016; REZENDE; CUNHA, 2005; FERREIRA, 2009; FARIA, 2009).

Em geral, entende-se que um modelo de gestão para resultados deve ser multidimensional (BOYNE et al., 2006; NEELY, 2007), ou seja, deve levar em conta suas múltiplas dimensões de esforço (processos, recursos, estruturas, sistemas informacionais e, principalmente, pessoas) para alinhá-los aos resultados. Em termos gerais, percebe-se ser imperativo que um modelo ideal de gestão para resultados se baseie em um conceito abrangente de desempenho, incluindo dimensões de esforço e de resultados (MARTINS; MARINI, 2010).

Desde 1996, a gestão fiscal subnacional brasileira vem obtendo avanços significativos na definição de políticas e prioridades, de acordo com a Cogef (2016),

\footnotetext{
1 A palavra resultado é em geral utilizada para designar coisas tão diferentes quanto produtos preliminares, intermediários, finais, efeitos e impactos (RUA, 2007).

${ }^{2}$ O NPM trouxe reformas gerenciais dirigidas para a adaptação e a transferência dos conhecimentos gerenciais desenvolvidos no setor privado para o público, envolvendo a redução do tamanho da máquina administrativa, o aumento de sua eficiência e a criação de mecanismos voltados à responsabilização dos atores políticos (COGEF, 2016).

${ }^{3}$ Incluiu a eficiência como um dos princípios a ser obedecido por todos os poderes da União, dos Estados, do Distrito Federal e dos municípios, tornando inquestionável a preocupação com resultados e a entrega de serviços de qualidade e com o custo adequado.

${ }^{4}$ Lei complementar N. 101/2000 que estabelece normas de finanças públicas voltadas à responsabilidade na gestão fiscal, pressupondo uma ação planejada e transparente, em que se previnem riscos e se corrigem desvios capazes de afetar o equilíbrio das contas públicas.
} 
isto vem ocorrendo entre outras coisas, pela implementação de programas que visam modernizar a gestão fazendária brasileira. Entre os anos de 1996 e 2006, ocorreu o primeiro ciclo de modernização fiscal, promovido pelo Programa Nacional de Apoio à Modernização Fiscal (PNAFE) financiado pelo Banco Interamericano de Desenvolvimento (BID), e pelo Programa de Modernização da Administração Fiscal (PMAT) realizado com recursos do Banco Nacional Desenvolvimento Econômico Sustentável (BNDES).

O segundo ciclo iniciado em 2009, está sendo executado por meio do Programa de Apoio à Gestão e Integração dos Fiscos no Brasil (Profisco), cujos recursos estão sendo custeados pelo BID, já tendo ultrapassado os US\$ 600 milhões, emprestados a 22 estados, o Distrito Federal e o Ministério da Fazenda (Quadro 1), dados atualizados até dezembro de 2017. 


\section{Quadro 1 - Distribuição dos recursos do Profisco/BID por Estado, valores, status e MD-GEFIS}

\begin{tabular}{|c|c|c|c|c|c|}
\hline $\begin{array}{l}\text { Ente } \\
\text { Recebedor }\end{array}$ & $\begin{array}{l}\text { Valor Total do } \\
\text { Empréstimo }\end{array}$ & Data Início & $\begin{array}{c}\text { Data } \\
\text { Término }\end{array}$ & Status & $\begin{array}{l}\text { Aplicação da } \\
\text { MD-GEFIS }\end{array}$ \\
\hline Minas Gerais & 44.000 .000 & $26 / 02 / 2010$ & $23 / 12 / 2014$ & Concluído & Não \\
\hline Pará & 11.000 .000 & $28 / 09 / 2009$ & $28 / 09 / 2014$ & Concluído & Sim \\
\hline Ceará & 45.100 .000 & $20 / 05 / 2010$ & $20 / 05 / 2016$ & Concluído & $\operatorname{Sim}$ \\
\hline Rio de Janeiro & 21.734 .955 & $10 / 05 / 2010$ & $10 / 05 / 2016$ & Concluído & Não \\
\hline Pernambuco & 16.500 .000 & $13 / 07 / 2010$ & $13 / 06 / 2016$ & Concluído & $\operatorname{Sim}$ \\
\hline Piauí & 18.646 .100 & $22 / 10 / 2010$ & $23 / 10 / 2016$ & Concluído & Sim \\
\hline Maranhão & 14.520 .000 & $29 / 09 / 2010$ & $29 / 09 / 2016$ & Concluído & Sim \\
\hline Santa Catarina & 33.000 .000 & $01 / 09 / 2010$ & $01 / 09 / 2016$ & Concluído & $\operatorname{Sim}$ \\
\hline Mato Grosso do Sul & 13.200 .000 & $29 / 10 / 2010$ & $29 / 10 / 2016$ & Concluído & Sim \\
\hline São Paulo & 32.000 .000 & $27 / 09 / 2010$ & $27 / 09 / 2017$ & Andamento & Sim \\
\hline Rio Grande do Sul & 66.000 .000 & $29 / 08 / 2010$ & $29 / 08 / 2016$ & Andamento & Sim \\
\hline Rio Grande do Norte & 7.700 .000 & $24 / 04 / 2013$ & $24 / 04 / 2017$ & Andamento & Sim \\
\hline Rondônia & 6.854 .100 & $25 / 05 / 2012$ & $25 / 05 / 2017$ & Andamento & $\operatorname{Sim}$ \\
\hline Espírito Santo & 24.191 .200 & $05 / 11 / 2010$ & $05 / 11 / 2017$ & Andamento & Sim \\
\hline Paraíba & 8.226 .900 & $18 / 05 / 2012$ & $17 / 05 / 2017$ & Andamento & Não \\
\hline Goiás & 12.734 .700 & $23 / 08 / 2013$ & $23 / 08 / 2017$ & Andamento & Não \\
\hline Tocantins & 44.474 .100 & $19 / 10 / 2012$ & $19 / 10 / 2019$ & Andamento & Não \\
\hline Mato Grosso & 16.535 .200 & $20 / 12 / 2012$ & $20 / 12 / 2016$ & Andamento & Não \\
\hline Alagoas & 7.700 .000 & $23 / 12 / 2013$ & $23 / 12 / 2018$ & Andamento & Não \\
\hline Sergipe & 6.366 .800 & $30 / 08 / 2013$ & $30 / 08 / 2018$ & Andamento & Não \\
\hline Bahia & 49.797 .000 & $17 / 12 / 2013$ & $17 / 12 / 2018$ & Andamento & Não \\
\hline Paraná & 9.350 .000 & $06 / 08 / 2014$ & 06/08/2019 & Andamento & Sim \\
\hline Distrito Federal & 35.196 .700 & $29 / 02 / 2016$ & $29 / 02 / 2021$ & Andamento & Não \\
\hline Subtotal & 644.827 .755 & & & & \\
\hline Min. da Fazenda & 21.780 .000 & $28 / 03 / 2014$ & 28/03/2019 & Andamento & Não \\
\hline TOTAL & 666.607 .755 & & & & 13 \\
\hline
\end{tabular}

Fonte: Elaborado pelos autores com dados oficiais, 2018.

Um terceiro ciclo de investimentos da mesma natureza está sendo viabilizado pelo BID atualmente. Denominado de Profisco II, esse programa prevê a liberação de aproximadamente US\$900 milhões, para financiamento por meio da linha CCLIP (sigla em inglês para linha de crédito condicional para projetos de investimentos). Neste caso, podem pleitear estes recursos, os entes que já concluíram ou estão com mais de $80 \%$ de execução do atual programa, ou aqueles que não o receberam.

Nota-se que os recursos oferecidos pelo BID, com fins de modernizar a gestão fiscal no Brasil, somando-se os dois ciclos do Profisco, passam de US\$ 1,5 bilhão. Trazendo a questão da gestão pública por resultados e o aumento da cobrança por 
parte da sociedade por uma administração mais transparente, monitorar e avaliar a gestão torna-se importantíssimo.

Sobre a questão da monitoração e da avaliação de processos, Rua (2003) afirma que estes se referem ao uso de um conjunto de estratégias para efetuar o "acompanhamento de uma política, programa ou projeto, de modo a identificar de maneira oportuna e tempestivamente as vantagens e pontos frágeis na sua execução, a fim de efetuar os ajustes e correções necessárias à maximização dos seus resultados e impactos" (p. 6).

Buscando relacionar a responsabilidade fiscal com a responsabilidade social e traçar um histórico, a partir da implementação da LRF/2000, Faria (2009) elaborou um estudo em que analisou o desempenho dos Estados brasileiros sob a ótica da gestão fiscal responsável e da qualidade de vida da sociedade. Como resultado, a autora obteve indícios de que a gestão fiscal baseada nos parâmetros dessa lei não garante a eficiência na prestação dos serviços públicos.

Conclui-se, aqui, que um modelo ideal de gestão para resultados deve estar embasado em um amplo conceito de desempenho, incluindo os esforços e os resultados. Sendo assim, considerando as teorias de gestão pública para resultados, no âmbito da gestão fiscal, a avaliação deve se basear nas mesmas premissas dimensionais de desempenho com esforço e resultado.

Sobre essa perspectiva, a MD-GEFIS tem como enunciado básico, o entendimento de que a melhoria do desempenho da organização é resultado de um conjunto de processos eficientes, isto é, que atendam aos requisitos dos benchmarkings nacionais e internacionais. Sendo assim, o objetivo principal deste modelo é contribuir para melhorar os resultados da gestão fiscal subnacional, em específico os que são relacionados ao aumento da transparência, ao incremento da arrecadação e à eficiência do gasto público.

A MD-GEFIS foi formulada com fins de oferecer aos gestores fazendários uma ferramenta possível de ser autoaplicável, considerando que uma gestão fiscal eficiente compreende três eixos ${ }^{5}$ de atuação que devem ser avaliados de forma harmônica e integrada, sendo:

- Eixo 1. Gestão Fazendária e Transparência Fiscal (GF): considera que a melhoria da governança pública na área fiscal depende de medidas como planejamento estratégico e avaliação do desempenho institucional; gerenciamento dos riscos; estímulo à participação e ao controle social por meio da transparência e prestação de contas; fortalecimento do controle interno e externo; desenvolvimento de pessoas e formação de sucessores com foco nas competências; compartilhamento

\footnotetext{
${ }^{5}$ Em 2014, o BID, atendendo a uma solicitação do Confaz e da SE/MF, auxiliou o governo federal a formular as Diretrizes e Recomendações Técnicas para Aperfeiçoamento da Gestão Fiscal dos Estados Brasileiros, que veio a ser aprovado por meio do Convênio de Cooperação do Confaz de 26 de dezembro de 2014. Essas diretrizes definiram os três eixos de gestão fiscal, norteadores da elaboração da MD-GEFIS.
} 
de informações e de soluções inovadoras; e utilização dos recursos de tecnologias de informação e de comunicação.

- Eixo 2. Administração Tributária e Contencioso Fiscal (AT): considera que o cumprimento voluntário das obrigações tributárias pode ser estimulado com a simplificação das obrigações acessórias e do pagamento de impostos; a análise dos riscos e da brecha tributária; a padronização de normas e procedimentos, particularmente em relação aos regimes especiais de tributação; do tratamento e utilização de informações digitais; da simplificação e celeridade do contencioso; da cobrança da dívida ativa e da transparência dos atos e decisões.

- Eixo 3. Administração Financeira e Gasto Público (AF): o fortalecimento da administração financeira estadual demanda a adoção de novas estratégias em áreas críticas tais como planejamento e avaliação de investimentos; gerenciamento de custos e de compras governamentais; avaliação da qualidade e dos resultados do gasto público; controle de dívida e de passivos contingentes, especialmente os relativos aos precatórios, à previdência pública e aos compromissos vinculados aos contratos de parcerias público-privadas (COGEF, 2016).

Cada um desses eixos é composto por um conjunto de seis dimensão críticas, tendo a estrutura de medição em três níveis (Figura 1), sendo: $1^{\circ}$ ) analisa a maturidade dos processos de negócios da gestão fiscal; $2^{\circ}$ ) analisa o desempenho da gestão fiscal por meio de indicadores definidos para cada uma das dimensões que compõem os eixos de atuação; e $3^{\circ}$ ) analisa os indicadores de impacto definidos para cada um dos eixos de atuação.

\section{Figura 1 - Estrutura do Modelo e de Medição da MD-GEFIS}

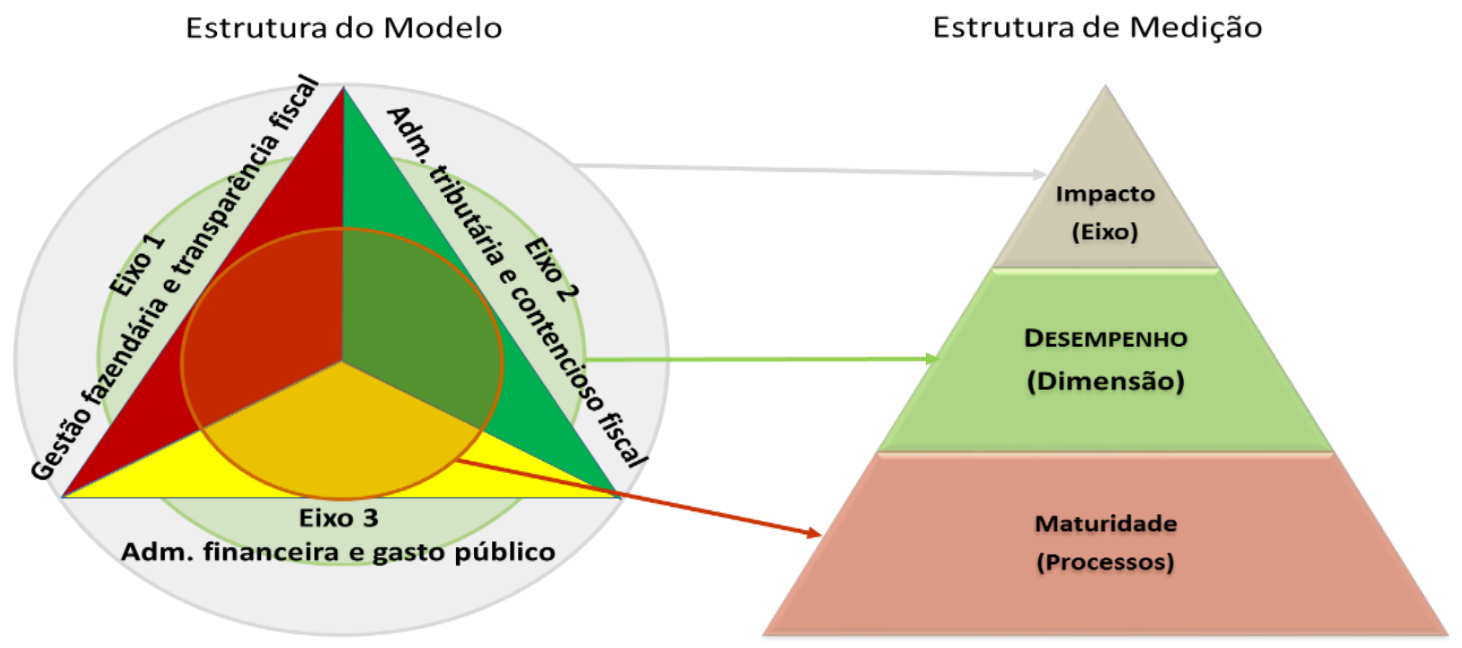

Fonte: COGEF, 2016. 
Os indicadores relativos aos três níveis da estrutura de medição são:

- De maturidade do processo: focaliza as dimensões mais importantes da cadeia de valor da gestão fiscal. Para cada uma dessas dimensões são indicados os processos e relacionados os requisitos do nível mais elevado de maturidade, ou seja, o benchmark dos processos.

- De desempenho: avalia quantitativamente os resultados alcançados com a maturidade do conjunto dos processos organizacionais, isto é, a performance organizacional.

- De impacto: a metodologia e os indicadores de avaliação de impacto ainda estão em construção, e serão realizados por especialistas independentes (COGEF, 2016).

Esses indicadores, de acordo com a Cogef (2017) são baseados nas melhores práticas nacionais e internacionais, tanto da gestão fazendária e da transparência fiscal quanto da administração tributária e financeira, contribuindo para a melhoria do desempenho da governança e gestão fiscal subnacional. Em resumo, quanto maior o grau de maturidade de processos da organização, melhor a performance gerencial fazendária.

\section{Procedimentos metodológicos}

Metodologicamente, a natureza deste trabalho é quantitativa e qualitativa, e os tipos de investigação são a exploratória ${ }^{6}$ por meio de revisão da literatura via pesquisa bibliográfica, e a descritiva ${ }^{7}$ por meio da aplicação de questionário semiestruturado, objetivando descrever e explicar as características do fenômeno analisado e estabelecer relações entre as variáveis estudadas, buscando assim demostrar qual a percepção que estes têm da MD-GEFIS.

Considerando que até o fim de 2017 esse modelo já tinha sido aplicado em 14 estados, e que, em média, as equipes são compostas por quatro pessoas, a proposta foi enviar o questionário para todos, no caso, 56 indivíduos. Visando garantir o sigilo aos respondentes, um código numérico foi distribuído aleatoriamente aos mesmos, sendo identificados apenas como AF (Agente Fazendário) e o número com o qual foi sorteado, por exemplo: AF.21.

O questionário utilizado foi o semiestruturado, com perguntas fechadas e abertas, aplicado on-line via formulário do Google Forms. A primeira parte coletou os dados do respondente, visando traçar o perfil profissional deste. A segunda levantou a

\footnotetext{
${ }^{6}$ De acordo com Matias-Pereira (2010) "por meio da análise da literatura publicada, é possível traçar um quadro teórico e conceitual que dará sustentação ao desenvolvimento da pesquisa” (p. 69).

7 Conforme Gil (2002, p. 28), a pesquisa que "têm como objetivo primordial a descrição das características de determinada população ou fenômeno ou o estabelecimento de relações entre variáveis” é descritiva.
} 
percepção dos agentes fazendários sobre a eficácia da MD-GEFIS e sua utilização como instrumento de gestão.

As perguntas fechadas tiveram uma escola de 0 a $10^{8}$, com a tabulação em Excel, calculando o percentual da gradação atribuída pelos respondentes às opções dadas, seguindo uma escala de cinco pontos: de 0 a 2 - ineficaz, de 3 a 4 - pouco eficaz, de 5 a 6 - parcialmente eficaz, de 7 a 8 - eficaz, e de 9 a 10 - muito eficaz. $O$ tratamento quantitativo das perguntas cujas respostas foram, "Sim", "Não" ou "Talvez", também foi no Excel, calculando-se o percentual de cada grupo de respostas escolhido. Já para as respostas dos "Por quêe?" (questões abertas), a análise de conteúdo deu-se por meio do software WebQDA ${ }^{9}$ versão 3.0. O Quadro 2, com as categorias de análise de conteúdo embasadas teoricamente, serviu como orientador desta etapa, cuja elaboração seguiu os conceitos de Bardin (2009) ${ }^{10}$.

\footnotetext{
${ }^{8}$ Gil (1999) aponta que escala de tipo Likert tem característica ordinal e sua elaboração é simples, prestando-se a registrar a concordância ou discordância com o enunciado. Normalmente, o contínuo de uma escala de Likert varia de 5 a 7 pontos.

${ }^{9}$ WebQDA (Web Qualitative Data Analysis), software de análise qualitativa de dados em ambiente colaborativo e distribuído. Desenvolvido pela Universidade de Aveiro em Portugal, pode ser trabalhado em um ambiente de colaboração entre pesquisadores, é disponibilizado por meio da internet, não sendo necessário baixá-lo em uma máquina em específico. O software é composto por três eixos: fontes, codificação e questionamento (SOUZA, COSTA e SOUZA, 2012).

10 Para Bardin, análise de conteúdo é "um conjunto de técnicas de análise das comunicações visando obter por procedimentos sistemáticos e objetivos de descrição do conteúdo das mensagens, indicadores (quantitativos ou não) que permitam a inferência de conhecimentos relativos às condições de produção/recepção (variáveis inferidas) destas mensagens" (2009, p. 44).
} 


\section{Quadro 2 - Dimensão, categorias e subcategorias para análise de conteúdo dos questionários respondidos}

\begin{tabular}{|c|c|c|c|}
\hline Dimensão & Categorias & Subcategorias & Questões \\
\hline & & $\begin{array}{l}\text { 1.1 Área de formação } \\
\text { 1.2 Organização em que trabalha } \\
\text { 1.3 Cargo que exerce } \\
\text { 1.4 Cidade de localização }\end{array}$ & Dados do respondente \\
\hline \multirow{6}{*}{ Eficácia } & \multirow{6}{*}{$\begin{array}{l}\text { C.2 } \\
\text { Identificação } \\
\text { da eficácia da } \\
\text { MD-GEFIS }\end{array}$} & 2.1 Instrumento de autoavaliação & $\begin{array}{l}\text { 1. Percepção quanto à funcionalidade da MD- } \\
\text { GEFIS como instrumento de autoavaliação }\end{array}$ \\
\hline & & $\begin{array}{l}\text { 2.2 Clareza das perguntas do } \\
\text { questionário do modelo }\end{array}$ & $\begin{array}{l}\text { 2. Clareza quanto às perguntas elaboradas no } \\
\text { questionário da MD-GEFIS }\end{array}$ \\
\hline & & $\begin{array}{l}\text { 2.3 Característica de eficácia do } \\
\text { modelo na melhoria de resultados }\end{array}$ & $\begin{array}{l}\text { 7. Identificação das características mais } \\
\text { eficazes da MD-GEFIS: contribuir para a } \\
\text { melhoria dos resultados da gestão fiscal }\end{array}$ \\
\hline & & $\begin{array}{l}\text { 2.4 Característica de eficácia do } \\
\text { modelo no aumento da } \\
\text { transparência }\end{array}$ & $\begin{array}{l}\text { 7. Identificação das características mais } \\
\text { eficazes da MD-GEFIS: contribuir para o } \\
\text { aumento da transparência da gestão fiscal }\end{array}$ \\
\hline & & $\begin{array}{l}2.5 \text { Característica de eficácia do } \\
\text { modelo no aumento da } \\
\text { arrecadação }\end{array}$ & $\begin{array}{l}\text { 7. Identificação das características mais } \\
\text { eficazes da MD-GEFIS: contribuir para o } \\
\text { aumento da arrecadação }\end{array}$ \\
\hline & & $\begin{array}{l}\text { 2.6 Característica de eficácia do } \\
\text { modelo no aumento da eficiência }\end{array}$ & $\begin{array}{l}\text { 7. Identificação das características mais } \\
\text { eficazes da MD-GEFIS: contribuir para o } \\
\text { aumento da eficiência do gasto público }\end{array}$ \\
\hline \multirow{8}{*}{$\begin{array}{l}\text { Governança } \\
\text { pública para } \\
\text { resultados }\end{array}$} & \multirow{5}{*}{$\begin{array}{l}\text { C.3 } \\
\text { A MD-GEFIS } \\
\text { como } \\
\text { instrumento } \\
\text { de tomada de } \\
\text { decisão }\end{array}$} & $\begin{array}{l}\text { 3.1 Instrumento de tomada de } \\
\text { decisão de gestão fiscal no } \\
\text { desenho de novos projetos }\end{array}$ & $\begin{array}{l}\text { 6. Identificação da MD-GEFIS como } \\
\text { ferramenta para tomada de decisão quanto: } \\
\text { apoio ao desenho de projetos de } \\
\text { modernização }\end{array}$ \\
\hline & & $\begin{array}{l}\text { 3.2 Instrumento de tomada de } \\
\text { decisão de gestão fiscal como } \\
\text { subsídio para pleitos de novos } \\
\text { financiamentos } \\
\end{array}$ & $\begin{array}{l}\text { 6. Identificação da MD-GEFIS como } \\
\text { ferramenta para tomada de decisão quanto: } \\
\text { subsídio para pleito de financiamento } \\
\text { nacionais e internacionais }\end{array}$ \\
\hline & & $\begin{array}{l}\text { 3.3 Instrumento de tomada de } \\
\text { decisão de gestão fiscal como } \\
\text { subsídio para modernização }\end{array}$ & $\begin{array}{l}\text { 6. Identificação da MD-GEFIS como } \\
\text { ferramenta para tomada de decisão quanto: } \\
\text { subsídio de iniciativas de modernização } \\
\text { fazendária }\end{array}$ \\
\hline & & $\begin{array}{l}\text { 3.4 Instrumento de tomada de } \\
\text { decisão de gestão fiscal para } \\
\text { priorizar iniciativas de } \\
\text { modernização }\end{array}$ & $\begin{array}{l}\text { 6. Identificação da MD-GEFIS como } \\
\text { ferramenta para tomada de decisão quanto: } \\
\text { priorização de iniciativas de modernização } \\
\text { fazendária }\end{array}$ \\
\hline & & $\begin{array}{l}\text { 3.5 Instrumento de tomada de } \\
\text { decisão de gestão fiscal para } \\
\text { nortear aplicação de recursos }\end{array}$ & $\begin{array}{l}\text { 6. Identificação da MD-GEFIS como } \\
\text { ferramenta para tomada de decisão quanto: } \\
\text { norteamento da alocação de recursos públicos }\end{array}$ \\
\hline & \multirow{3}{*}{$\begin{array}{l}\text { C. } 4 \\
\text { A MD-GEFIS } \\
\text { identificando } \\
\text { a maturidade } \\
\text { da Gestão } \\
\text { Fiscal }\end{array}$} & $\begin{array}{l}\text { 4.1 Instrumento monitoramento } \\
\text { da maturidade da gestão fiscal }\end{array}$ & $\begin{array}{l}\text { 3. Percepção da MD-GEFIS para apoio ao } \\
\text { monitoramento da evolução da maturidade } \\
\text { dos processos da gestão fiscal }\end{array}$ \\
\hline & & $\begin{array}{l}\text { 4.2 Relevância como instrumento } \\
\text { de avaliação da maturidade da } \\
\text { gestão fiscal }\end{array}$ & $\begin{array}{l}\text { 5. Identificação do grau de importância da } \\
\text { MD-GEFIS como ferramenta de avaliação do } \\
\text { nível de maturidade da gestão fiscal }\end{array}$ \\
\hline & & $\begin{array}{l}4.3 \text { Instrumento de identificação } \\
\text { do nível de maturidade da gestão } \\
\text { fiscal }\end{array}$ & $\begin{array}{l}\text { 9. Percepção dos resultados da MD-GEFIS } \\
\text { como identificação do nível de maturidade } \\
\text { nos processos de gestão fiscal. }\end{array}$ \\
\hline
\end{tabular}




\begin{tabular}{|c|c|c|}
\hline $\begin{array}{l}\text { C.5 } \\
\text { A MD-GEFIS } \\
\text { como } \\
\text { ferramenta de }\end{array}$ & $\begin{array}{l}\text { 5.1 Instrumento de tomada de } \\
\text { decisão de gestão fiscal na } \\
\text { melhoria do desempenho da } \\
\text { gestão }\end{array}$ & $\begin{array}{l}\text { 4. Percepção da MD-GEFIS como linha de } \\
\text { base para ser utilizado na promoção da } \\
\text { melhoria do desempenho da gestão fiscal }\end{array}$ \\
\hline $\begin{array}{l}\text { gestão pública } \\
\text { para } \\
\text { resultados }\end{array}$ & $\begin{array}{l}5.2 \text { Instrumento de tomada de } \\
\text { decisão de gestão fiscal a partir da } \\
\text { identificação dos pontos fortes e } \\
\text { fracos }\end{array}$ & $\begin{array}{l}\text { 8. Identificação dos pontos fortes e fracos da } \\
\text { gestão fiscal }\end{array}$ \\
\hline
\end{tabular}

Fonte: Elaborado pelos autores.

A escolha do software WebQda se deu por ser uma ferramenta on-line, o que permite trabalhar em qualquer computador conectado à internet, não sendo necessário baixar o programa. Além disso, pela possibilita de trabalhar de forma colaborativa, permitindo que outras pessoas interajam no tratamento e análise da pesquisa, ampliando assim, a possibilidade de outros pesquisadores remotamente participarem do trabalho.

Os três eixos estruturantes do WebQda, que auxiliam na análise de conteúdo são: as fontes (onde os dados/textos são inseridos, neste caso, as respostas dadas pelos agentes fazendários às perguntas abertas); a codificação (onde se estabelecem as dimensões, categorias e subcategorias de codificação das fontes que norteiam as análises); e o questionamento (eixo em que é feita a matriz de análise, cruzando as respostas com a teoria abordada) (SOUZA, COSTA e SOUZA, 2012; FREITAS et al., 2016).

A metodologia de aplicação da MD-GEFIS, é a coleta de dados oriundos de questionários respondidos em planilhas de Excel, chamados de Matriz para Avaliação de Maturidade dos Processos e Indicadores e Matriz de Descrição dos Atributos dos Indicadores de Desempenho. Para esta parte, a equipe coordenada pelo BID conta com o auxílio das Unidades de Coordenação de Projetos do Profisco (UCP/UGP-PROFISCO) ${ }^{11}$, na aplicação da avaliação e coleta das respostas e evidências que servirão de base de dados dos indicadores da MD-GEFIS (COGEF, 2017). Salienta-se que o objetivo do presente estudo não é aplicar o modelo em questão, mas analisar por meio da percepção dos gestores do Profisco se essa avaliação tem sido eficaz e se tem atendido aos seus objetivos, isto sob a ótica da eficácia e da governança pública para resultados.

\footnotetext{
${ }^{11}$ Uma das obrigações dos entes tomadores de recursos relativos ao programa Profisco, definidas pelo BID, é que estes criem em sua organização uma Unidade de Coordenação de Projetos (UCP). Os responsáveis pela UCP além de serem o elo do Estado com o BID, também são os representantes na Cogef.
} 


\section{Análise e discussão dos resultados}

Do total de 23 Estados e Distrito Federal (Quadro 01) beneficiados com o programa de modernização fazendária, em 13 já foi aplicada a MD-GEFIS. Nota-se que o Amapá não recebeu empréstimo do Profisco em vigor, contudo, está pleiteando recursos do Profisco II, e, por isso, foi realizada a aplicação dessa avaliação no estado (COGEF, 2017).

Considerando que até o fim de 2017 essa avaliação já tinha sido aplicada em 14 estados, e que, em média, as equipes de gestão do Profisco são compostas por quatro pessoas, neste caso tem-se um total de 56 pessoas. Contudo, de acordo com a lista de "Quem é Quem"12, disponível no site da Cogef, dois desses grupos tem três componentes, ao invés de quatro, sendo assim, o total de indivíduos envolvidos na pesquisa foi 54. Ponderando esse universo amostral, foi enviado e-mail para todos contendo o questionário on-line no Google Forms com prazo inicial para respostas do dia 20 a 30 de novembro de 2017. Buscando obter o máximo de respostas possíveis, esse prazo foi estendido para 29 de dezembro do mesmo ano.

Ao término do prazo, foram respondidos 29 questionários, o que corresponde a $54 \%$ do total enviado. Nem todos os componentes das equipes responderam às perguntas, contudo, obteve-se resposta de todas as 14 unidades questionadas. Isso possibilita ter uma visão de todos os órgãos que aplicaram a avaliação, haja vista que obtivemos respostas de cada um deles.

Ao observarmos os resultados da primeira parte do questionário, relativa à Categoria C.1 - Informações profissionais, constata-se que 27 dos 29 respondentes se apresentaram como vinculados à Secretaria de Fazenda/Tributária de seus respectivos estados. Em resumo, o Gráfico 1 traz uma distribuição por formação, considerando esses cinco campos a mais, dando um total de 34 áreas de graduação.

\footnotetext{
12 Por orientação do BID, as equipes de gestão dos Profisco, denominadas de Unidade de Coordenação/Gerência de Projetos (UCP/UGP), devem ter uma estrutura mínima composta por um coordenador geral, um coordenador técnico, um coordenador administrativo financeiro e um assessor de monitoramento e avaliação. De acordo com a relação de "Quem é Quem" das equipes do Profisco, de julho de 2017, com os nomes, cargos e e-mails dos componentes. Disponível em: http://www.cogef.ms.gov.br/wp-content/uploads/2014/11/COGEF-QUEM\%C3\%89-QUEM-v072017.pdf.
} 


\section{Gráfico 1 - Distribuição dos respondentes por área de formação}

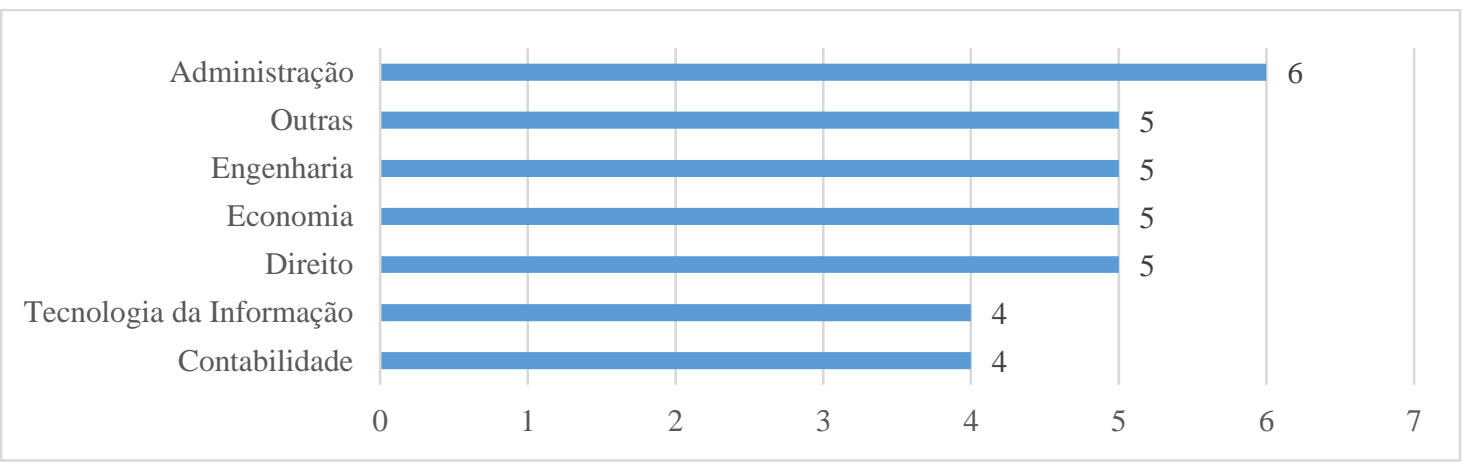

Fonte: Elaborado pelos autores.

Nota-se que a Administração com seis profissionais é o campo com maior quantitativo nas equipes, seguidos de Engenharia, Economia e Direito com cinco, respectivamente. Na categoria "Outras" foram agrupadas: Arquitetura e Urbanismo (1), Comunicação Social (1), Psicologia (1), Sociologia (1). Em Tecnologia da Informação agrupou-se formações correlatas como Ciência da Computação e Análise de Sistemas. No Gráfico 2, tem-se a distribuição dos respondentes por cargo ocupado.

\section{Gráfico 2 - Distribuição dos respondentes por cargo ocupado}

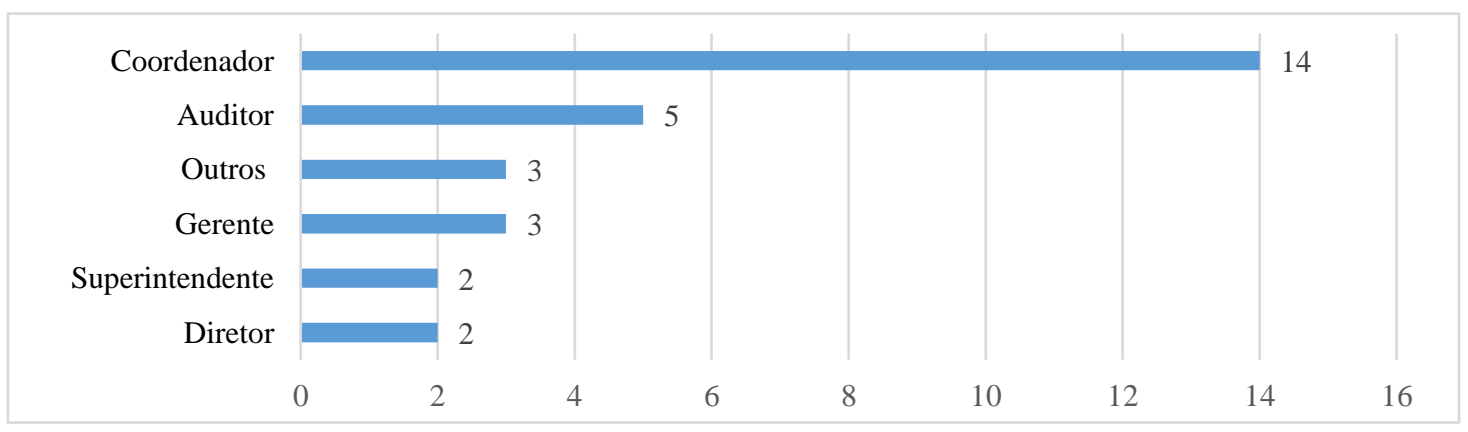

Fonte: Elaborado pelos autores.

Ao observar o Gráfico 2, nota-se que a maioria dos agentes que responderam à pesquisa estão no cargo de coordenação, e os demais estão distribuídos entre as ocupações de auditoria (cinco), gerência (três), superintendência (dois) e diretoria (dois), entre outras. Considerando que a pesquisa foi feita junto aos membros das equipes das UCP, deduz-se que a maioria das respostas foram fornecidas pelos coordenadores dessas unidades. Os resultados da análise da segunda parte do questionário são demonstrados nos próximos tópicos. 


\section{Dimensão de eficácia}

A Categoria C.2 - Identificação da eficácia da MD-GEFIS tratou dos resultados das perguntas 1, 2 e 7 do questionário, sendo que a opinião dos respondentes, quanto à eficácia da MD-GEFIS como ferramenta de autoavaliação e clareza de seus questionamentos, refere-se às primeiras, cujos resultados podem ser vistos nos Quadros 3 e 4.

\section{Quadro 3 - Eficácia da MD-GEFIS como instrumento de autoavaliação da gestão fiscal subnacional}

\begin{tabular}{|l|c|c|c|c|c|}
\hline \multirow{2}{*}{$\begin{array}{l}\text { Respostas por } \\
\text { escala de eficácia }\end{array}$} & Ineficaz & Pouco eficaz & $\begin{array}{c}\text { Parcialmente } \\
\text { eficaz }\end{array}$ & Eficaz & Muito eficaz \\
\cline { 2 - 6 } & 0 a 2 & 3 a 4 & 5 a 6 & 7 a 8 & 9 a 10 \\
\hline 29 & 0 & 0 & 1 & 14 & 14 \\
\hline $100 \%$ & $0 \%$ & $0 \%$ & $3,44 \%$ & $48,28 \%$ & $48,28 \%$ \\
\hline
\end{tabular}

Fonte: Elaborado pelos autores.

$\mathrm{Na}$ percepção da maioria (Quadro 3), o modelo de avaliação da maturidade fazendária enquanto ferramenta de autoaplicação é mais que eficaz. Apenas um dos respondentes o considera parcialmente eficaz. A princípio, esses resultados levam a concluir que, na opinião dos agentes fazendários, há a certeza da sua eficácia como instrumento de autoavaliação.

Contudo, com a análise das respostas dadas, percebe-se que para alguns, embora o instrumento possa ser autoaplicado, em certos casos ficou de difícil entendimento por acharem o questionário subjetivo. Para outros, como AF. 15:

O MD-GEFIS quando respondido sob orientação de um especialista no instrumento permite uma autoavaliação mais imparcial. Acredito que respondê-lo sem essa orientação pode levar a uma autoavaliação condescendente com possíveis aspectos negativos da realidade da gestão fiscal.

Outros agentes não vincularam suas respostas de eficácia ao critério de autoavaliação, mas ao fato de considerarem que o instrumento propicia à gestão uma visão mais ampla da situação da administração fazendária.

Quanto à eficácia da MD-GEFIS no que se refere ao quão claro suas questões estão formuladas (Quadro 4), para a maioria ela é eficaz ou muito eficaz. Mas, nota-se, que pouco mais de 13\% entendem que, neste quesito, o modelo é parcial ou pouco eficaz. 
Quadro 4 - Eficácia da MD-GEFIS quanto à clareza das perguntas de seu questionário

\begin{tabular}{|l|c|c|c|c|c|}
\hline \multirow{2}{*}{$\begin{array}{l}\text { Respostas por } \\
\text { escala de eficácia }\end{array}$} & Ineficaz & Pouco eficaz & $\begin{array}{c}\text { Parcialmente } \\
\text { eficaz }\end{array}$ & Eficaz & Muito eficaz \\
\cline { 2 - 6 } & 0 a 2 & 3 a 4 & 5 a 6 & 7 a 8 & 9 a 10 \\
\hline 29 & 0 & 1 & 3 & 16 & 9 \\
\hline $100 \%$ & $0 \%$ & $3,44 \%$ & $10,35 \%$ & $55,17 \%$ & $31,04 \%$ \\
\hline
\end{tabular}

Fonte: Elaborado pelos autores.

$\mathrm{Na}$ análise do conteúdo das respostas deste item, percebeu-se que, embora os respondentes tenham atribuído um elevado grau de eficácia à clareza do questionário do modelo, ao explicarem o motivo de suas notas, eles apontaram algumas falhas, por exemplo: AF. 7: "A maioria são bem claras e objetivas, mas algumas apresentam certo grau de subjetividade que geram alguma dúvida”; e AF. 20: "Em alguns pontos, os questionamentos não são tão claros e dão margem a dúvidas". E ainda a necessidade de um glossário para melhor entender os conceitos inerentes às perguntas (AF. 21).

Outra questão que aborda a análise de eficácia é a sete, que tratou de identificar as características consideradas pelos agentes fazendários como as mais eficazes da MD-GEFIS, a partir de quatro atributos apontados inicialmente e com a possibilidade de o respondente indicar outra que na sua opinião fosse mais eficaz.

\section{Gráfico 3 - Característica mais eficaz da MD-GEFIS}

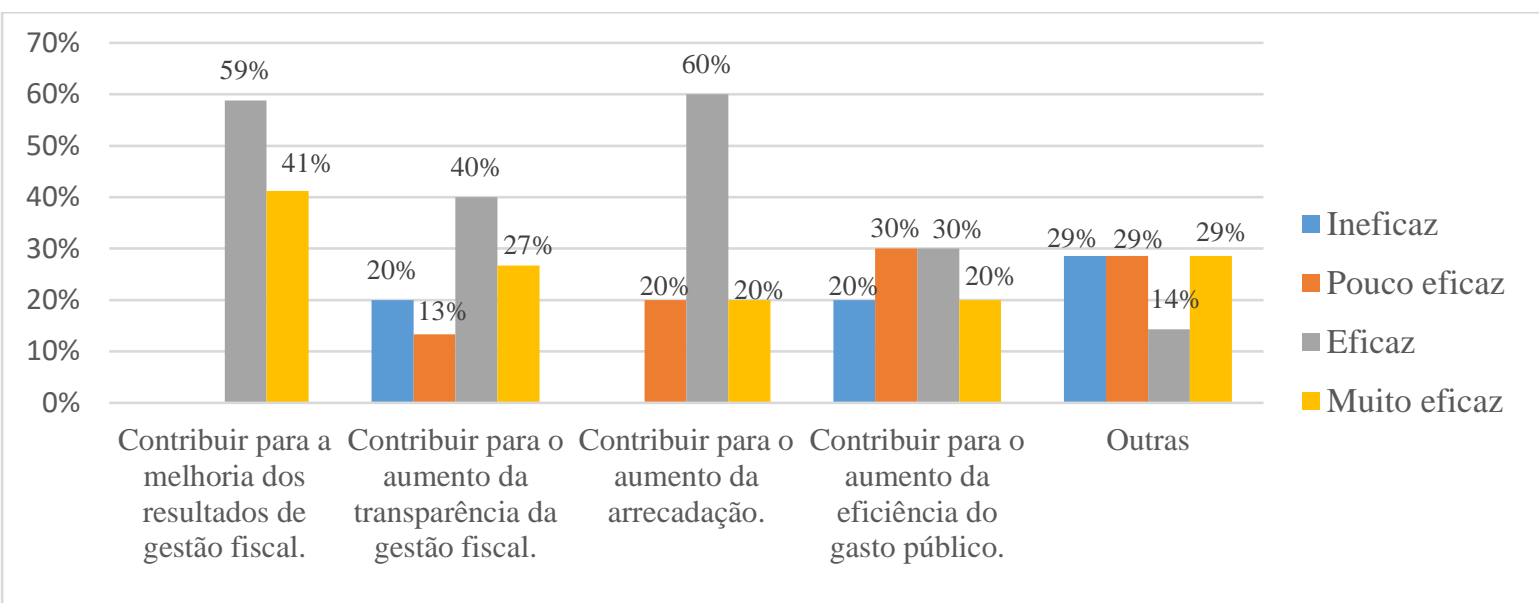

Fonte: Elaborado pelos autores.

Ao observarmos o Gráfico 3 percebe-se que as características apontadas como as mais eficazes foram: contribuir para o aumento da arrecadação e para a melhoria 
dos resultados de gestão fiscal. A terceira característica com maior gradação foi contribuir para o aumento da transparência da gestão fiscal. Em quarto lugar ficou a de contribuir para o aumento da eficiência do gasto público.

Vale destacar que nesta questão houve uma menor quantidade de participantes, sendo que 17 marcaram seu grau de preferência na primeira característica, 15 na segunda, 10 na segunda e terceira e sete em Outras. Isso pode ter ocorrido pela dificuldade que alguns encontraram ao responder à questão. Por exemplo: AF.24 afirmou que não foi possível marcar "mais de uma opção como Muito Eficaz e nem a desmarcação de opção incorreta". Outro respondeu que a questão estava complexa e "como não é possível marcar 'Eficaz' para mais de um, usei uma escala de eficácia".

A dificuldade em marcar mais de uma opção na grade de preferências, pode ser um dos motivos do baixo quantitativo de pessoas que responderam à esta questão no formulário. Contudo, para os que fizeram a gradação da questão e responderam sobre os motivos, alguns afirmaram que a MD-GEFIS é eficaz por dar subsídios para a gestão fazendária direcionar e tomar decisões. Também, por que "contribui muito para a melhoria dos resultados, aumento da transparência e aumento da arrecadação. A eficiência do gasto depende de outras variáveis que sobre as quais a gestão fiscal não tem total governança” (AF.19).

\section{Dimensão de Governança Pública para Resultados}

A dimensão de Governança Pública para Resultados foi dividia em três categorias de análise, como demonstrado a seguir.

A Categoria C.3 - a MD-GEFIS como instrumento de tomada de decisão, buscou analisar a opinião dos agentes fazendários quanto ao grau de eficácia da MDGEFIS, enquanto ferramenta para que a gestão fiscal estadual tome decisões. Neste caso, foram apresentadas cinco sugestões e a possibilidade de os respondentes indicarem outra de sua preferência (questão 6 do questionário). 


\section{Gráfico 4 - A MD-GEFIS como instrumento de tomada de decisão da gestão fiscal subnacional}

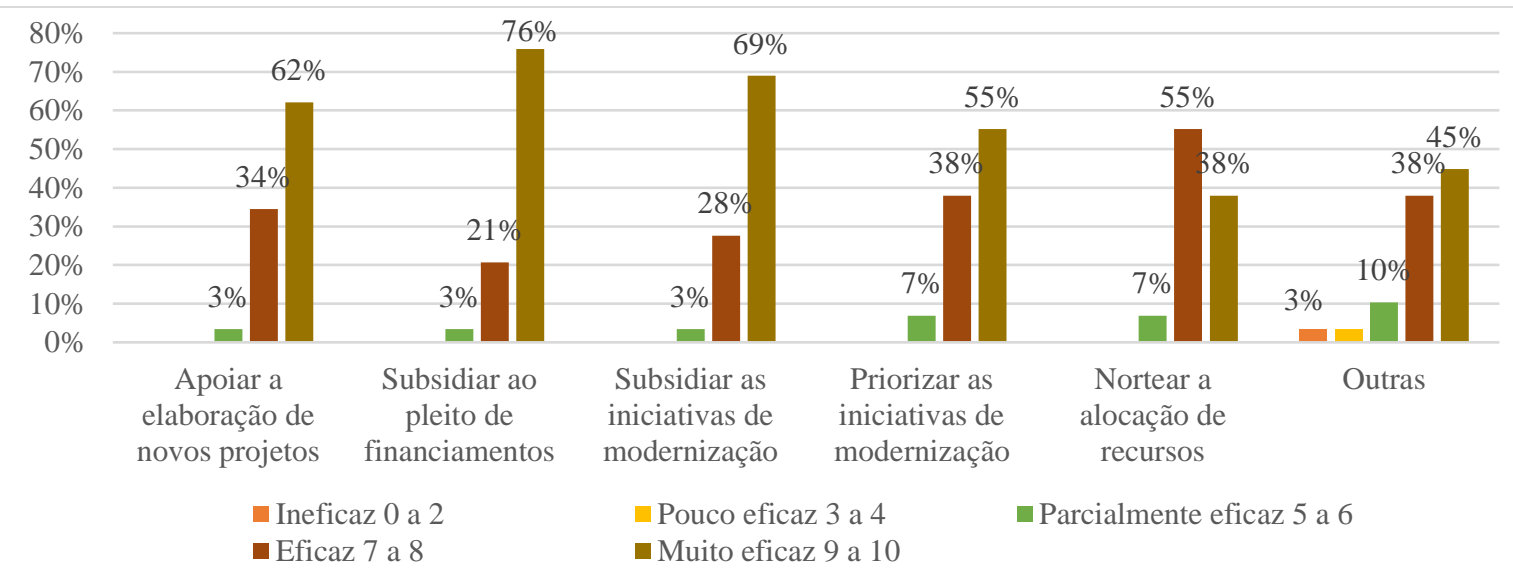

Fonte: Elaborado pelos autores.

No Gráfico 4 é possível perceber que que a maioria dos respondentes consideraram que o resultado da MD-GEFIS é "Muito eficaz" no processo decisório da gestão fazendária para subsidiar nos pedidos de financiamentos, nas iniciativas de modernizar a gestão, na elaboração de novos projetos, bem como na priorização de ações de modernização.

No que se refere à tomada de decisão para nortear a alocação de recursos, 55\% dos respondentes consideram que o resultado dessa avaliação é "Eficaz", e 38\% que é "Muito eficaz". Nesse quesito, houve a gradação de eficácia na opção "Outras", contudo, nenhum dos respondentes indicaram qual seria essa funcionalidade. Para esta questão, apenas um agente fazendário deu resposta, afirmando que “(...) muitos pontos identificados pela metodologia já estavam no plano de ação, isto mostra que o instrumento é bom" (AF.7).

A categoria C.4 - a MD-GEFIS como identificador da maturidade da gestão fiscal subnacional foi analisada com base nas respostas às Questões 3, 5 e 9. A questão 3, buscou identificar qual a percepção que os agentes fazendários têm da eficácia da MD-GEFIS enquanto ferramenta auxiliar para monitorar a evolução da maturidade de processos (Quadro 5). 
Quadro 5 - A MD-GEFIS como instrumento de apoio ao monitoramento da evolução da maturidade dos processos da gestão fiscal subnacional

\begin{tabular}{|l|c|c|c|c|c|}
\hline \multirow{2}{*}{$\begin{array}{l}\text { Respostas por } \\
\text { escala de eficácia }\end{array}$} & Ineficaz & Pouco eficaz & $\begin{array}{c}\text { Parcialmente } \\
\text { eficaz }\end{array}$ & Eficaz & Muito eficaz \\
\cline { 2 - 6 } & 0 a 2 & 3 a 4 & 5 a 6 & 7 a 8 & 9 a 10 \\
\hline 29 & 0 & 0 & 0 & 15 & 14 \\
\hline $100 \%$ & $0 \%$ & $0 \%$ & $0 \%$ & $52 \%$ & $48 \%$ \\
\hline
\end{tabular}

Fonte: Elaborado pelos autores.

No Quadro 5 os resultados demonstram que como ferramenta de acompanhamento dos avanços do amadurecimento da gestão em sua organização, a MD-GEFIS é mais que eficaz, ao somar os percentuais de "Eficaz" (52\%) e "Muito eficaz" (48\%).

Esse entendimento de eficácia foi ratificado nas respostas descritivas dos agentes fazendários, que, além disso, apontaram a necessidade de continuidade de aplicação desta metodologia, como destaca AF. 19 ao dizer que "a aplicação periódica da MDGEFIS permitirá monitorar de forma eficaz os avanços na qualidade dos processos da gestão fiscal dos Estados". E ainda que, "ao utilizar as boas práticas como parâmetro, com a estruturação através de indicadores, a ferramenta possibilita monitoramento da evolução, fornecendo uma análise situacional (ponto 0) e posterior acompanhamento" (AF. 9). Também, pode criar na organização "uma cultura interna de monitoramento baseada em indicadores que a metodologia traz" (AF. 21). No entanto, AF. 12, chama a atenção, para o fato de que, esses indicadores são de avaliação de "processos internos (...) é fundamental que os indicadores que guiam os projetos e as tarefas da administração pública sejam relacionados a algum resultado direto ao cidadão".

A percepção dos agentes quanto ao grau de relevância da MD-GEFIS, como instrumento para avaliar o nível de amadurecimento de suas organizações, foi trata na Questão 06, e seus resultados estão apresentados no Quadro 6, a seguir:

Quadro 6 - Importância da MD-GEFIS como ferramenta de avaliação do nível de maturidade da gestão fiscal subnacional

\begin{tabular}{|l|c|c|c|c|c|}
\hline \multirow{2}{*}{$\begin{array}{l}\text { Respostas por } \\
\text { escala de eficácia }\end{array}$} & $\begin{array}{c}\text { Sem } \\
\text { importância }\end{array}$ & $\begin{array}{c}\text { Pouco } \\
\text { importante }\end{array}$ & $\begin{array}{c}\text { Parcialmente } \\
\text { importante }\end{array}$ & Importante & $\begin{array}{c}\text { Muito } \\
\text { importante }\end{array}$ \\
\cline { 2 - 6 } & 0 a 2 & $3 \mathrm{a} 4$ & 5 a 6 & 7 a 8 & 9 a 10 \\
\hline 29 & 0 & 0 & 1 & 13 & 15 \\
\hline $100 \%$ & $0 \%$ & $0 \%$ & $3,44 \%$ & $44,84 \%$ & $51,72 \%$ \\
\hline
\end{tabular}

Fonte: Elaborado pelos autores. 
Aqui também os resultados demonstraram que a maioria dos respondentes atribuíram alto grau de importância a MD-GEFIS enquanto instrumento para avaliar o amadurecimento da gestão fazendária. Com a análise do conteúdo das repostas, notou-se que, em geral, isso se dá devido ao fato dela considerar e abranger todas as áreas/atividades da gestão fiscal (AF. 16; AF. 6) e permitir ter uma visão ampla/geral/total das "diversas administrações fazendárias do país" (AF. 27), e do "quão maduros os fiscos estão" (AF. 28). Pois também "expressa as melhores práticas de gestão a serem tomadas como referência" (AF. 4), e ainda por dar uma contextualização da organização, "pois quem não sabe onde está, dificilmente consegue chegar a algum lugar” (AF.26).

Já AF.23, pondera que a proposta de padronização de maturidade apresentada pela MD-GEFIS "permite uma comparabilidade entre os Estados subnacionais, guardadas as especificidades contextuais e históricas de cada um, que precisam ser consideradas qualitativamente nas análises de maturidade" (AF. 23). Os indicadores de maturidade, resultantes da aplicação do modelo, precisam ser analisados de forma crítica e "devem ser voltados para resultados para o cidadão, para o contribuinte, para a qualidade do gasto e a qualidade da receita" (AF.12). Além disso, "a divulgação desse índice é muito interessante se não mudar a essência, visto que uma vez divulgado os secretários podem influenciar para que a nota aumente/diminua de acordo com o momento político" (AF.3).

Observando os resultados relativos questão 8 da Categoria C.4, constata-se que para 93\% dos respondentes (Gráfico 5) essa ferramenta permite apontar as fraquezas e as fortalezas da gestão fazendária.

\section{Gráfico 5 - A MD-GEFIS como instrumento de identificação dos pontos fortes e fracos da gestão fiscal subnacional}

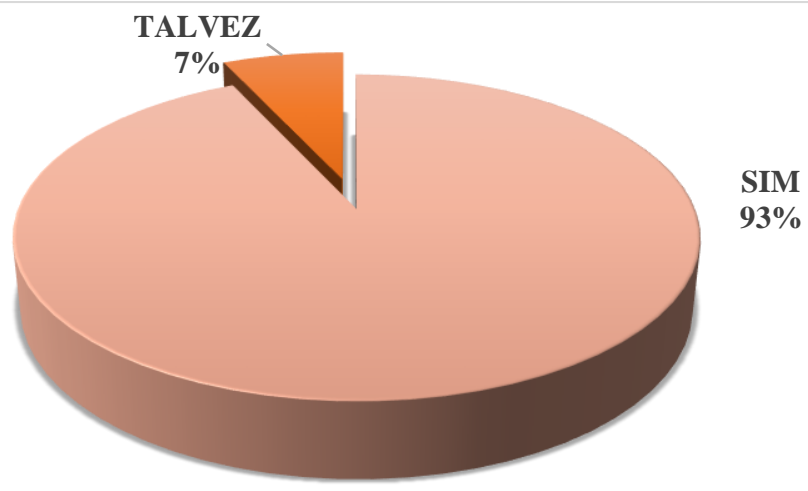

Fonte: Elaborado pelos autores.

$\mathrm{Na}$ análise das respostas dos "Talvez", nota-se que essa atribuição na opinião do AF. 25 é devido ao fato de que o instrumento evidenciou mais os pontos fracos do 
que os fortes. E segundo AF.8, as perguntas dos questionamentos feitos eram confusas.

Em termos gerais, a maioria dos pontos fortes e fracos é identificada pela metodologia: a objetividade do modelo, com respostas sim ou não, que permite expor a situação da gestão, as falhas e carências, e permite compará-lo às melhores práticas (AF.10; AF.6; AF.14; AF.24; AF.19). Permite, ainda, fazer uma "reflexão ampla sobre todo instrumento, todo o processo de gestão fiscal, apontando espaços de melhoria" (AF. 23). Contudo, AF.27 alerta para o fato de se considerar as especificidades de cada órgão, objetivando assim "evitar conclusões equivocadas sobre os resultados apresentados".

Prosseguindo, tem-se os resultados da análise da Categoria C.5 - a MD-GEFIS como ferramenta de gestão pública para resultados (Quadro 7), que se refere à questão 9. Neste caso, a maioria das respostas indicam que essa ferramenta é muito eficaz enquanto formadora de linha de base na promoção da melhoria da gestão fazendária dos estados.

\section{Quadro 7 - Resultados da MD-GEFIS como linha de base para promover a melhoria do desempenho da gestão fiscal subnacional}

\begin{tabular}{|l|c|c|c|c|c|}
\hline \multirow{2}{*}{$\begin{array}{l}\text { Respostas por } \\
\text { escala de eficácia }\end{array}$} & Ineficaz & Pouco eficaz & $\begin{array}{c}\text { Parcialmente } \\
\text { eficaz }\end{array}$ & Eficaz & Muito eficaz \\
\cline { 2 - 6 } & 0 a 2 & 3 a 4 & 5 a 6 & 7 a 8 & 9 a 10 \\
\hline 29 & 0 & 0 & 0 & 12 & 17 \\
\hline 100 & $0 \%$ & $0 \%$ & $0 \%$ & $41,38 \%$ & $58,62 \%$ \\
\hline
\end{tabular}

Fonte: Elaborado pelos autores.

O respondente AF.1 justificou sua gradação, afirmando que é "porque dá um bom diagnóstico da realidade da organização na área fiscal". Já para AF.24 "é como se tivéssemos uma fotografia que pudesse ser melhorada como a comparação do ANTES e DEPOIS". E para AF.23 é porque cria "um ponto de referência sólido. Contudo, na afirmação de AF.21, essa ferramenta necessita de aperfeiçoamento para ser um instrumento de gerência.

Alguns respondentes afirmaram que a sua eficácia se dá pelo fato de que "tais resultados podem propiciar a montagem mais definida de um Planejamento Estratégico" (AF.29). AF.3 respondeu que é porque a relação de "prioridades e a carteira de projetos levará em consideração a MD-GEFIS”. AF.28, acrescenta que além do Planejamento Estratégico, também a Visão de Futuro da Secretaria pode utilizar destes resultados.

Embora considere a eficácia desse instrumento, nesta funcionalidade, AF. 12 acredita que o questionamento está incorreto, na medida em que "os valores de 
linha de base para cada indicador, por si só, não colaboram em promover a melhoria dos processos e o consequente desempenho da gestão fiscal". No entanto, continua ele, é relevante para planejar os "projetos de melhoria (...), para que haja uma identificação dos pontos fracos, das oportunidades de melhoria e, a partir daí a preparação de projetos para a mudança destes processos" (AF.12).

Já AF. 19, afirma que à medida que, periodicamente, essa avaliação seja aplicada nos estados, seus resultados possibilitarão medir melhoras na performance da gestão fiscal "por meio da comparação dos indicadores de desempenho constantes do instrumento, tanto com resultados do próprio estado aferidos em períodos anteriores, quanto com resultados de outros estados, caso a MD-GEFIS evolua para se tornar um ranking entre os estados".

A última questão analisada nesta categoria foi a 9, cujo questionamento é: o (a) Sr.(a) diria que os resultados da MD-GEFIS em sua organização permitem identificar o nível de maturidade nos processos de gestão fiscal?

\section{Gráfico 6 - A MD-GEFIS como instrumento de identificação do nível de maturidade nos processos de gestão fiscal}

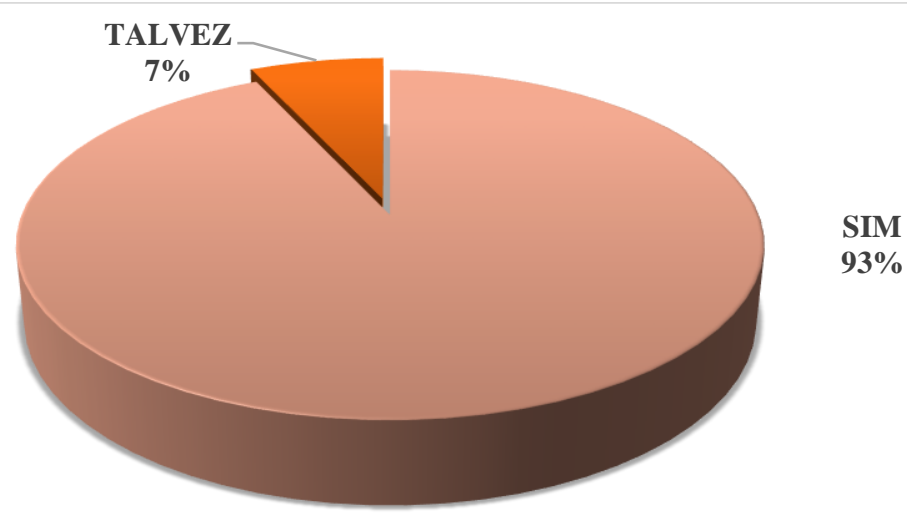

Fonte: Elaborado pelos autores.

No Gráfico 6, verificamos que apenas $7 \%$ dos agentes fazendários marcaram "Talvez". Nesse sentido, AF.28 justificou sua resposta, afirmando que como consequência da avaliação é possível ter uma noção do amadurecimento fazendário local. No entanto, se o nível for de pouca maturidade, continua ele "fica difícil mensurar se a causa é um processo executado de forma ineficiente na dimensão analisada ou se há algo relevante a aprimorar, que não seja vinculada aos processos" (AF.28).

Contudo, para a maioria dos agentes fazendários os resultados da MD-GEFIS permitem "Sim" identificar o nível de maturidade nos processos de gestão fiscal em suas organizações. Em termos gerais, eles apontaram entre outras coisas, que é 
porque essa avaliação demonstra a realidade e os problemas em suas organizações, e compara o que é praticado atualmente com as melhores práticas executadas tanto nacional quanto internacionalmente (AF.21; AF.25; AF.24; AF.4; AF.23; AF. 19).

A metodologia de avaliação da MD-GEFIS exige evidências (comprovações documentais) das respostas dadas pelos participantes. Na opinião de AF.15, essa condição "faz com que a mensuração de resultados seja mais objetiva. Evitando-se respostas positivas sem a devida comprovação de existência material daquilo que foi afirmado pelo gestor".

Para o respondente AF.12, a MD-GEFIS conseguirá demonstrar o grau de amadurecimento da gestão fazendária avaliada, se os procedimentos de "coleta dos indicadores e das boas práticas" for realizado corretamente, gerando assim, resultados confiáveis e fidedignos. Já para AF.27, as especificidades de cada gestão fiscal devem ser consideradas para que essa ferramenta efetue uma avaliação sem ressalvas.

Além de permitir as inferências, como demonstrado nas análises dos resultados do questionário, o uso do software WebQda permitiu a identificação das 50 palavras ditas com mais frequência nos textos analisados. Para esta seleção, fez-se a opção de busca de palavras com mais de sete caracteres, cujo resultado é destacado na Figura 2 .

\section{Figura 2-As 50 palavras mais frequentes}

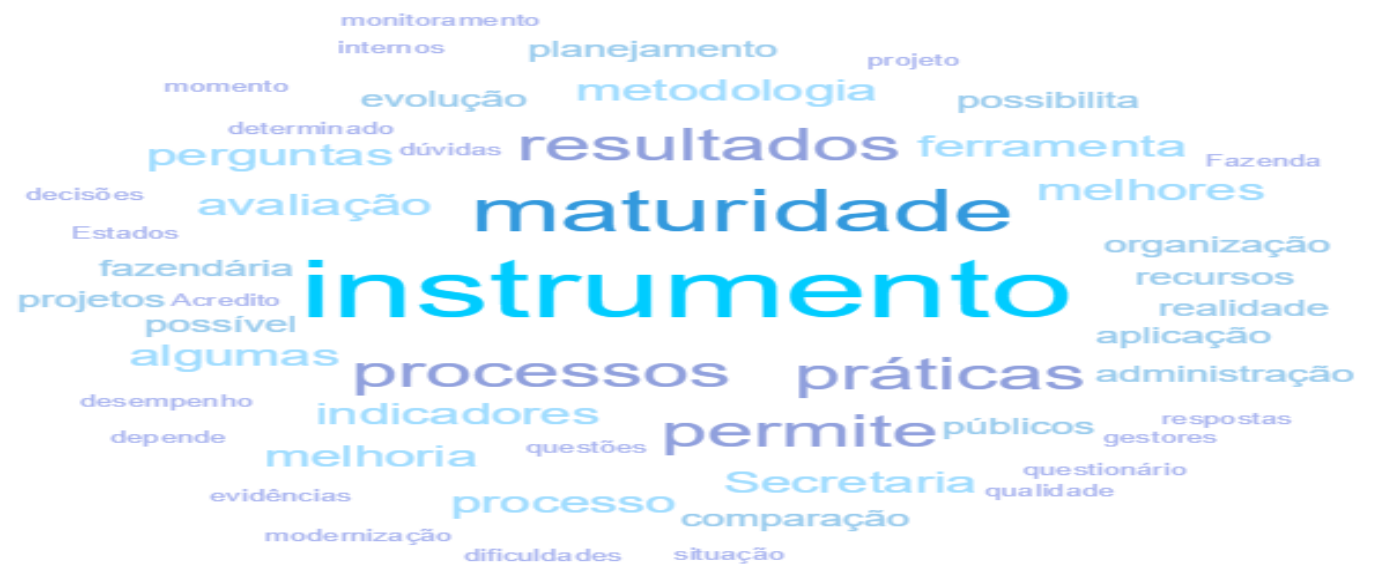

Fonte: WebQda com Elaborado pelos autores.

Conforme pode-se observar na Figura 2, a palavra mais referenciada pelos respondentes foi "instrumento", com 40 citações. Em seguida, destacamos outras cinco com citações acima de 20 vezes: maturidade (28); processos (22); práticas (21); permite (20); e resultados (20). 
Algumas citações da palavra "instrumento" foram feitas vinculada a uma percepção positiva, relacionada a adjetivos como: bom, muito bom, muito bem, ótimo, excelente e útil. Porém, analisando, observamos que algumas dessas referências são relacionadas a algumas ponderações quanto à limitação, falhas, subjetividade, entre outras, como se percebe nas falas dos seguintes agentes fazendários:

Muito bom instrumento de avaliação da gestão fiscal, que pode ser aprimorado (...) (AF.10).

O instrumento em si é excelente, mas a escala adotada precisa melhorar (AF.6).

Em contrapartida, além dessa percepção positiva e ponderada, destaca-se algumas menções relativas: a larga abrangência no levantamento dos processos, das ações e da gestão fiscal; a possibilidade de refletir e retratar a realidade fazendária dos estados; a identificação de benchmarks, entre outras.

\section{Considerações finais}

A proposta deste trabalho foi demonstrar em que medida a ferramenta de avaliação do nível de Maturidade e Desempenho da Gestão Fiscal (MD-GEFIS), na opinião dos agentes fazendários participantes, é eficaz como instrumento de governança da gestão fiscal subnacional no Brasil. Para tal, foi aplicado um questionário junto a estes agentes com fins específicos de compreender, identificar e analisar a percepção dos mesmos quanto à eficácia da metodologia da MD-GEFIS às suas características de governança pública. E, sob a ótica da eficácia e governança no setor público, verificar se esse ferramental pode ser de considerado de gestão.

A primeira parte do questionário aplicado referiu-se ao perfil profissional dos respondentes, Categoria 1 da análise, e a constatação foi que $98 \%$ disseram ser servidores da Secretaria de Fazenda de seu Estado, sendo que a grande maioria é formada em Administração, Engenharia e Economia, e ocupam o cargo de Coordenador. A segunda, foi analisada sobre a ótica de duas dimensões, a da eficácia e a da gestão pública para resultados, subdivididas em categorias, cujo foco é atender aos objetivos específicos.

Os resultados da primeira dimensão permitiram identificar que as características mais eficazes da metodologia, na opinião dos respondentes são: contribuir para a melhoria dos resultados de gestão fiscal; colaborar para o aumento da arrecadação; e contribuir para o aumento da transparência da gestão fiscal. Contudo, algumas ressalvas 
A segunda dimensão - Governança Pública para Resultados foi analisada por meio da investigação de 3 categorias. Na primeira, os resultados encontrados demonstram essa metodologia é muito eficaz para subsidiar o processo decisório na solicitação de financiamentos, nas atividades de modernização, na preparação de projetos inovadores, e na priorização dos processos modernizadores, e ainda, para subsidiar a gestão em definir qual o direcionamento dar aos recursos públicos.

$\mathrm{Na}$ segunda, os resultados foram que todos os respondentes, consideram a metodologia eficaz como suporte para monitorar a evolução do amadurecimento dos processos da gestão fiscal, em virtude que ela abrange todas as áreas da administração fiscal estadual, permitindo, assim, ter uma visão ampla da maturidade da gestão fazendária nacional. Além disso, é relevante também porque apresenta o benchmarking nessas áreas, podendo servir de modelo a ser adotado. Outra percepção da maioria dos respondentes é que ela permite identificar os pontos fortes e fracos da gestão fiscal, possibilitando refletir sobre os procedimentos da gestão e indicar as lacunas existentes para se melhorar.

Com a análise da terceira categoria, aponta-se que para a maioria dos respondentes: a) os resultados dessa avaliação são muito eficazes para a formação da linha de base no fomento a uma melhor performance da gestão, devido ao excelente diagnóstico que esse método oferece, criando uma referência da situação organizacional do fisco, cujos resultados podem ser inseridos no planejamento estratégico do órgão; b) permitem identificar o grau de amadurecimento dos processos da gestão fazendária, já que evidenciam as dificuldades das organizações, bem como possibilitam comparar as benchmarking nacionais e internacionais.

Por fim, conclui-se neste estudo que em termos quantitativos, a MD-GEFIS é considerada pela maioria dos agentes fazendários que responderam a esta pesquisa como um eficaz instrumento de avaliação da gestão fazendária subnacional, o que é corroborado pelas respostas dadas.

Contudo, destaca-se alguns pontos que devem ser considerados: a) a importância da MD-GEFIS coletar corretamente os indicadores e as evidências das boas práticas para que se tenham resultado fiéis e de confiança; b) devem ser consideradas as características individuais de cada uma das unidades fazendárias subnacionais, para que não se tenham reservas quanto aos seus resultados, e ainda permitir a identificação das boas práticas adotadas pelos estados e possível evolução para um ranqueamento dos resultados; e c) sua aplicação necessitou ser conduzida por consultores externos à organização, o que descaracteriza a autoavaliação pretendida pela mesma. Neste caso, orienta-se que seja reavaliada se essa ferramenta pode ou não ser de autoavaliação, bem como que a publicidade dos resultados deve ser dada com a identificação dos estados, o que permitirá estudos mais acurados sobre essas avaliações. 


\section{Referências}

ARRETCHE, M. "Tendências no estudo sobre avaliação". In: RICO, E. M. (Org.) Avaliação de políticas sociais: uma questão em debate. São Paulo: Cortez, 1998. p. 29-39.

BARDIN, Laurence. Análise de conteúdo. Lisboa: Edições 70, 2009.

BOYNE, G. et al. Public service performance: perspectives on measurement and management. Cambridge/UK: Cambridge University Press, 2006. Disponível em:

http://assets.cambridge.org/97805211/72936/frontmatter/9780521172936_front matter.pdf. Acesso em: 19 nov. 2017.

BRASIL. Tribunal de Contas da União. Diagnóstico e perfil de maturidade dos sistemas de avaliação de programas governamentais. Brasília, DF: TCU, 2014. Disponível em:

http://portal2.tcu.gov.br/portal/pls/portal/docs/2666622.PDF. Acesso em: 24 jun. 2017.

COGEF. Maturidade e desempenho da gestão fiscal (MD-GEFIS): modelo conceitual para avaliação da gestão fiscal dos estados e do Distrito Federal (= mimeo.). S. 1.: Comissão de Gestão Fazendária, 2017.

COGEF. Maturidade e desempenho da gestão fiscal (MD-GEFIS): modelo conceitual para avaliação da gestão fiscal dos estados e do Distrito Federal (= mimeo.). S. 1.: Comissão de Gestão Fazendária, 2016.

FARIA, D. M. Gestão fiscal responsável e qualidade de vida da sociedade: uma análise do desempenho dos estados brasileiros. 2009. Dissertação (Mestrado em Administração Pública) - Fundação Getúlio Vargas, Rio de Janeiro, 2009.

FERREIRA, A. R. Modelo de excelência em gestão pública no governo brasileiro: importância e aplicação. In: XIV Congreso Internacional del CLAD sobre la Reforma del Estado y de la Administración Pública, 2009, Salvador de Bahia. Anais... Salvador/BA: CLAD, 2009. p. 27-30. Disponível em: 
http://www.gespublica.gov.br/sites/default/files/documentos/ferrerib.pdf. Acesso em: 01 ago. 2017.

FIGUEIREDO, M. F.; FIGUEIREDO, A. M. C. Avaliação política e avaliação de políticas: um quadro de referência teórica. Análise \& Conjuntura, Belo Horizonte, vol. 1, n. 3, p. 107-127, 1986. Disponível em: http://www.josenorberto.com.br/AC-2007-38.pdf. Acesso em: 25 jun. 2017.

FREITAS, F. et al. O manual de utilizador de um software de análise qualitativa: as percepções dos utilizadores do WebQDA. RISTI, Porto, n. 19, p. 107-117, set. 2016. Disponível em:

http:/ / www.scielo.mec.pt/scielo.php?script=sci_arttext\&pid=S164698952016000300009\&lng=pt\&nrm=iso. Acesso em: 06 abr. 2018.

GIL, A. C. Métodos e técnicas de pesquisa social. 6 ed. São Paulo: Atlas, 2009.

GIL, A. C. Como elaborar projetos de pesquisa. 4 ed. São Paulo: Atlas, 2002.

MARTINS, H. F.; MARINI, C. Um guia de governança para resultados na administração pública. Brasilia/DF: Instituto Publix, 2010.

MATIAS-PEREIRA, J. Governança no setor público. São Paulo: Atlas, 2010.

NEELY, A. Business performance measurement: unifying theory and integrating practice. 2 ed. Cambridge/UK: Cambridge University Press, 2007. Disponível em: http://content.schweitzer-onlie.de/ static/catalog_manager/live/media_files/representation/zd_std_orig_zd_schw_ orig/002/183/245/9780521803427_table_of_content_pdf_1.pdf. Acesso em: 29 nov. 2017.

SOUZA, D. Neri de; COSTA, A. P.; SOUZA, F. Neri de. Avaliação da percepção dos formandos sobre o software WebQDA. In: II Congresso Internacional TIC e Educação, 2012, Lisboa. Anais... Lisboa: ticEDUCA2012, 2012. p. 365-376. Disponível em: https://webqda.net/wpcontent/uploads/2016/10/ Avaliacao PercecaoFormandos.pdf. Acesso em: 20 nov. 2017. 
OLIVEIRA, A. G.; PISA, B. J. IGovP: índice de avaliação da governança pública - instrumento de planejamento do Estado e de controle social pelo cidadão.

Revista de Administração Pública, Rio de Janeiro, vol. 49, n. 5, p. 1263-1290, 2015. Disponível em: http://www.spell.org.br/ documentos/ver/37290/igovp-indice-de-avaliacao-da-governanca-publica-instrumento-de-planejamento-doestado-e-de-controle-social-pelo-cidadao. Acesso em: 20 nov. 2017.

REZENDE, F. A.; CUNHA, A. M. Diplina fiscal e qualidade do gasto público: Fundamentos da Reforma Orçamentária. 1. ed. Rio de Janeiro: FGV, 2005.

RUA, M. das G. Avaliação no ciclo da gestão pública (= mimeo.). Brasília: ENAP, 2007.

RUA, M. da G. Avaliação de políticas, programas e projetos: notas introdutórias (= mimeo.). Brasília: ENAP, 2003. Disponível em: http://antigo.enap.gov.br/downloads/ec43ea4fUFAM-MariadasGraAvalia Pol.pdf. Acesso em 25 ago. de 2016. 
Data de submissão: $27 / 11 / 2020$

Data de aprovação: 04/06/2021

Revisão: Daniela Matthes (português), Anderson de Miranda Gomes (inglês) e Yanet María Reimondo Barrios (espanhol).

\author{
Maria Rosicleide Nascimento Araújo \\ Bacharela em Economia e Mestre em Desenvolvimento Regional \\ 106 Norte Avenida Lo 4, 115 - Plano Diretor Norte \\ 77006-050 Palmas/TO, Brasil \\ Orcid: http://orcid.org/0000-0002-2677-9185 \\ E-mail: rosicleidearaujo@hotmail.com \\ Mônica Aparecida Rocha Silva \\ Programa de Pós-Graduação em Desenvolvimento Regional / Universidade Federal \\ do Tocantins \\ Quadra 109 Norte, Avenida NS-15, ALCNO-14, Plano Diretor Norte \\ 77.001-090 Palmas/TO, Brasil \\ Orcid: http://orcid.org/0000-0002-3323-7712 \\ E-mail: monicars@uft.edu.br \\ Waldecy Rodrigues \\ Programa de Pós-Graduação em Desenvolvimento Regional / Universidade Federal \\ do Tocantins \\ Quadra 109 Norte, Avenida NS-15, ALCNO-14, Plano Diretor Norte \\ 77.001-090 Palmas/TO, Brasil \\ Orcid: http://orcid.org/0000-0002-5584-6586 \\ E-mail: waldecy@uft.edu.br
}

